\title{
Disease stability and extended dosing under anti-VEGF treatment of exudative age-related macular degeneration (AMD) - a meta-analysis
}

\author{
Justus G. Garweg ${ }^{1,2}$ (D) $\cdot$ Christin Gerhardt ${ }^{1}$ (i) \\ Received: 31 March 2020 / Revised: 2 December 2020 / Accepted: 4 December 2020 / Published online: 2 February 2021 \\ (C) The Author(s) 2021
}

\begin{abstract}
Purpose To assess disease stability (absence of intra- and/or subretinal fluid) and the portion of eyes being capable to extend their treatment interval to $\geq 12$ weeks in exudative age-related macular degeneration (AMD).

Methods A systematic literature search was performed in NCBI, PubMed, CENTRAL, and ClinicalTrials.gov to identify clinical studies reporting treatment outcomes for ranibizumab, aflibercept, and brolucizumab in exudative AMD under a treat-and-extend protocol and a follow-up of $\geq 12$ months. Weighted mean differences and subgroup comparisons were used to integrate the different studies.

Results This meta-analysis refers to 29 published series, including 27 independent samples and 5629 patients. In the pooled group, disease stability was reported in $62.9 \%$ and $56.0 \%$, respectively, after 12 and 24 months of treatment, whereas treatment intervals were extended to $\geq 12$ weeks in $37.7 \%$ and $42.6 \%$, respectively. Ranibizumab, aflibercept, and brolucizumab differed regarding their potential to achieve disease stability $(56.3 \%, 64.5 \%$, and $71.5 \%$ after 12 , and $50.0 \%, 52.7 \%$ and $75.7 \%$ after 24 months; $p=<0.001)$ and to allow an interval extension to $\geq 12$ weeks $(28.6 \%, 34.2 \%$, and $53.3 \%$ after 12 , and $34.2 \%, 47.7 \%$, and $41.7 \%$ after 24 months; $p=<0.001$ ).

Conclusion The portion of eyes achieving disease stability regressed in the second year, whereas the portion of eyes under $\mathrm{a} \geq 12$ week interval increased. This discrepancy may reflect the challenges in balancing between under-treatment and a reduced treatment burden.
\end{abstract}

\section{Key messages}

- The development of new anti-VEGF-agents and protocols for the treatment of wet AMD aims at an improved performance and reduced treatment burden.

- Ranibizumab, aflibercept and brolucizumab seem to similarly improve visual acuity under comparable treatment conditions (treat-and-extend protocol) for up to 24 months whereas a treatment interval extension to $\geq 12$ weeks is achieved in $34.2 \%, 47.7 \%$ and $41.7 \%$ after 24 months.

- If confirmed in real life, brolucizumab seems to more effectively reduceintra - and/or subretinal fluid in the long-term.

- The portion of eyes without intra - and/or subretinal fluid under ranibizumab and aflibercept is going back by 6.3-11.8\% in the second year, indicating the difficulty to balance between under-treatment and a reduced treatment burden.

Justus G. Garweg

Justus.garweg@augenklinik-bern.ch

1 Swiss Eye Institute, Rotkreuz, and Berner Augenklinik am Lindenhofspital, Bern, Switzerland

2 Department of Ophthalmology, Inselspital, University of Bern, Bern, Switzerland 
Keywords Age-related macular degeneration (AMD) $\cdot$ Neovascular AMD $\cdot$ Treat-and-extend $\cdot$ Ranibizumab $\cdot$ Aflibercept Brolucizumab

\section{Introduction}

The introduction of intravitreal anti-vascular endothelial growth factor (anti-VEGF) drugs at the beginning of this century has revolutionized the treatment of exudative maculopathies [1]. Ranibizumab (Ran; Lucentis ${ }^{\circledR}$, Genentech, South San Francisco, CA, USA) was the first intravitreal anti-VEGF treatment receiving FDA approval for the treatment of neovascular age-related macular degeneration (nAMD) in 2006 [2, 3]. By the time of its introduction, bevacizumab (Avastin ${ }^{\circledR}$, Genentech/Roche, Switzerland), approved for the systemic use in oncology, had been broadly and successfully used as a low-cost off-label intravitreal treatment alternative for macular edema of different pathophysiologies [4] showing a success rate similar to Ran [5], but not necessarily a comparably favorable safety profile [6-8]. Therefore, its reimbursement by health insurance systems was not granted in many countries. Early clinical research focused on reducing the treatment burden due to monthly visits and injections according to the label, and on improving patient adherence and functional outcomes [9-11] as well as the performance of the overcrowded outpatient clinics [12]. Soon, it became evident that an impressive short-term effect was lost after 2 years once the patients were switched to an as-needed or pro re nata (PRN) therapy $[13,14]$ that could hardly be explained by the progression of the underlying atrophying macular situation $[15,16]$. Based on the less enthusiastic real-life experience with long-term outcomes, research switched its focus on predisposing factors, treatment adherence, and treatment strategy modification [17-24]. When patients adhered to their treatment protocols, one-third still maintained a reading and driving vision over many years [25]. With aflibercept (Afl; Eylea®, Bayer, Berlin, Germany), a second treatment option became approved in late 2012 for the treatment of nAMD [26, 27], providing a new hope to overcome the limitations of long-term treatment. Since then, the discussion focused on the differences between the two drugs regarding their response in distinct lesion types, and the effect of switching treatment. A few months ago, the third anti-VEGF agent named brolucizumab (Bro; Beovu@, Novartis Inc., Basel, Switzerland) had been launched. The two approval studies (Harrier and Hawk [28, 29]) reported a more substantial effect on the reduction of retinal fluid and longer mean re-treatment intervals, promising less burden for patients and caregivers.

Whereas similar visual gains have been reported for the three drugs, a direct head-to-head comparison of their potential to dry the retina and enable extension of the treatment interval to 12 or more weeks was not available. This drove us to undertake a meta-analysis based on the published evidence. We investigated the potential of Ran, Afl, and Bro to achieve the absence of (intra- and/or sub-) retinal fluid and treatment intervals of $\geq$ 12 weeks based on comparable treatment conditions.

\section{Material and methods}

A systematic literature search was performed on May 14, 2020, in the NCBI/PubMed database from the National Institute of Health, USA (https://www.ncbi.nlm.nih.gov/pubmed), as well as in the Cochrane Central Register of Controlled Trials (CENTRAL) and on ClinicalTrials.gov, to identify pro- and retrospective studies retrieved by the key terms ((age-related macular degeneration OR wAMD OR exudative AMD) AND (treat and extend OR T\&E OR PRN OR pro re nata)). Furthermore, researchers in the field have been contacted for additional studies, and reference lists of meta-analyses and reviews have been screened for suitable articles. From the resulting set, all manuscripts published since 2008 were selected according to the inclusion criteria described below. Cross-references identified during a manual search of references from the retrieved articles were included if they provided additional data. Furthermore, several articles published on the same study could be included if they added additional information. However, only full-length articles in English were included. In contrast, articles reporting identical data from the same study, abstracts, letters to the editor, case reports, and review articles were excluded.

\section{Inclusion and exclusion criteria}

Criteria applied for studies to be considered eligible for this meta-analysis were:

1. Study design: prospective and retrospective clinical studies and case series with $\geq 40$ participants in total published or accepted between 2008 and 2020;

2. Population: treatment-naïve participants with exudative age-related macular degeneration (AMD) and a followup of at least 12 months;

3. Intervention: the following treatment schedules were accepted:

- Treat-and-extend (T\&E) protocol starting with three monthly loading injections (in case of disease stability, the treatment interval was extended by 2 to 4 weeks to a maximum of 16 weeks; in case of instability, the interval was shortened by 2 to 4 weeks)

- Fixed treatment schedule (monthly or bi-monthly) during the first year followed by T\&E protocol in the second year or capped PRN with mandatory 
treatment at least q12 weeks (in this case, only year 2 data were included)

For this study, a capped PRN protocol was accepted as used in the second year of the View studies and a primary extension to 12 weeks with the option to reduce the treatment interval to 8 weeks as in Harrier and Hawk trials as comparable to a T\&E protocol.

The following outcome variables were defined:

a. Proportion of eyes achieving disease stability (operationalized by the absence of intra- and/or subretinal fluid);

b. Proportion of eyes reaching dosing intervals of $\geq$ 12 weeks;

c. Best-corrected visual acuity and visual gain;

d. The number of injections and treatment retention rate.

\section{Information retrieved from the included studies}

Whenever information was missing in the published papers, we consulted ClinicalTrials.gov or other study registries for further information. We extracted the following information: identifier, name of the study, type of anti-VEGF-agent, subgroups or treatment arms, treatment regimen and interval, study design, individual study definition for stability of disease, demographics (age, gender, country), follow-up period, values for visual acuity, number of injections, indices for stability (macular fluid, treatment interval extension), and retention rate for 12- and 24-month follow-up. Wherever necessary, we converted visual acuity scores into the Early Treatment Diabetic Retinopathy Study (ETDRS) letters to ensure consistency. As mentioned above, only treatment arms meeting T\&E criteria or a fixed regimen followed by T\&E or capped PRN criteria were included. In contrast, exclusively fixed dosing and regular PRN groups were excluded. Each included treatment arm is represented in one line in Table 1. To calculate a meta-analysis on these data, we extracted both mean and standard deviation whenever possible. In cases where the standard deviation was missing, we calculated the weighted mean of the whole sample. We replaced the missing value by this estimation to avoid a loss of data.

\section{Statistical analysis}

For a demographic overview of our studies, we calculated weighted mean values for the demographics age and sex ratio and frequency distributions for the country of origin. For the meta-analytic integration of results, we calculated weighted mean differences using random-effects models (Comprehensive Meta-Analysis (CMA) [30]) for visual acuity scores at baseline and 12- and 24-month follow-up, and for the number of injections and visual gain at 12- and 24-months follow-up. Patient retention and stability criteria were analyzed using subgroup comparison. All scores were calculated across all included studies as well as on subgroup level to compare anti-VEGF-agents (Ran, Afl, Bro). Subgroup comparisons were performed using $\chi^{2}$ test.

\section{Results}

\section{Included studies}

The primary literature search returned a total of 767 references (Fig. 1). After exclusion of duplicates $(N=83)$ and the first screening on the titles and abstracts, 110 articles remained, to which we added another 23 by a manual search of reference lists. After full-text reading, 29 publications [28, 29, 31-59] describing 19 independent studies and including 27 independent samples fulfilled the inclusion criteria to be coded by two raters. Interrater reliability was calculated in order to show agreement between the two raters. Cohen's kappa [60] yielded 85\%, indicating a moderate to a high interrater agreement. Differences in data extraction were resolved by discussion. One study could be represented by multiple citations, if the supplemental articles added additional information on this study.

From the 29 reference studies, a total of 5629 patients from 27 independent samples with exudative AMD fulfilled the treatment protocol criteria and were included. The mean age was $76.8( \pm 8.3)$ years, $56.2 \%$ were females. Five studies included multinational cohorts $[28 ; 29 ; 31 ; 32,33 ; 34 ; 35 ; n=$ $3351]$, while 3 were from Australia $[36-38 ; 39 ; 40 ; n=672]$ and 2 each from Norway $[41-42 ; 43 ; n=268]$, the USA [56$57 ; 58 ; n=80]$, and Switzerland [44-45;46;n=465]. One sample each per country was added from Canada [47-49; $n=287$ ], China [50; $n=85]$, Finland [59; $n=26]$, Japan [51-54; $n=247]$, and the UK [55; $n=148]$. Further details regarding the single studies are displayed in Table 1.

\section{Treatment group comparison}

In the overall sample, intra- and/or subretinal fluid were absent in $62.9 \%$ and $56.0 \%$ after 12 and 24 months, respectively. Treatment could be extended to $\geq 12$-week intervals in $37.7 \%$ and $42.6 \%$ after 1 and 2 years of treatment, respectively. The retention rate of patients was overall high, yielding $>90 \%$ after year 1 and $>80 \%$ in year 2 indicating a high power of the data. After pooling of all data per drug, the groups differed regarding their potential to achieve a dry retina (absence of intra- and/or subretinal fluid) as an indicator of disease stability after 12 months $(\operatorname{Ran}=56.3 \%, \mathrm{Afl}=64.5 \%, \mathrm{Bro}=71.5 \%)$ and after 24 months $(\operatorname{Ran}=50.0 \%, \mathrm{Afl}=52.7 \%, \mathrm{Bro}=75.7 \%)$. Different numbers of patients were extended to $\geq 12$ weeks for each of the three drugs after 12 months $(\operatorname{Ran}=28.6 \%, \mathrm{Afl}=34.2 \%, \mathrm{Bro}=$ 


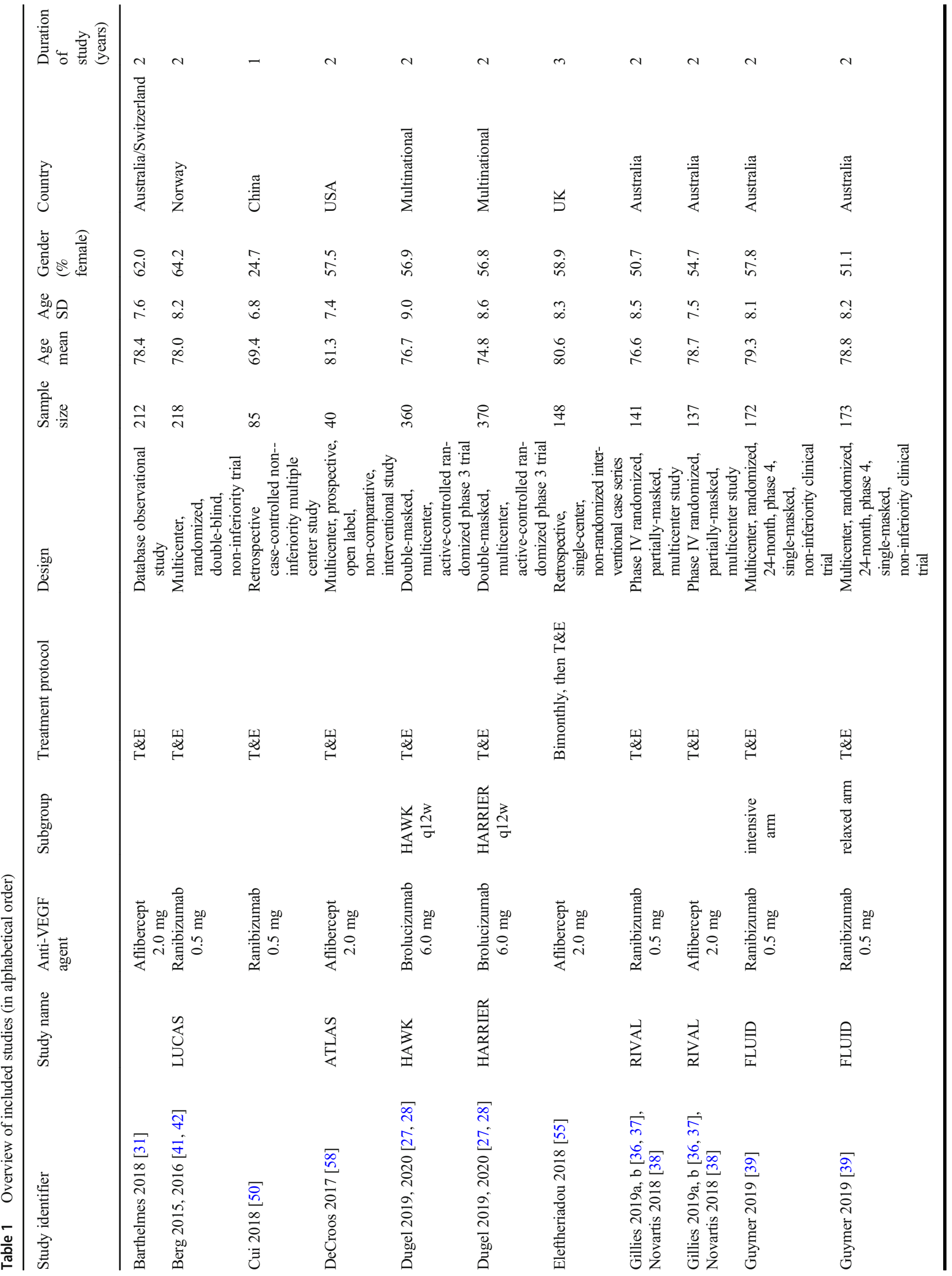




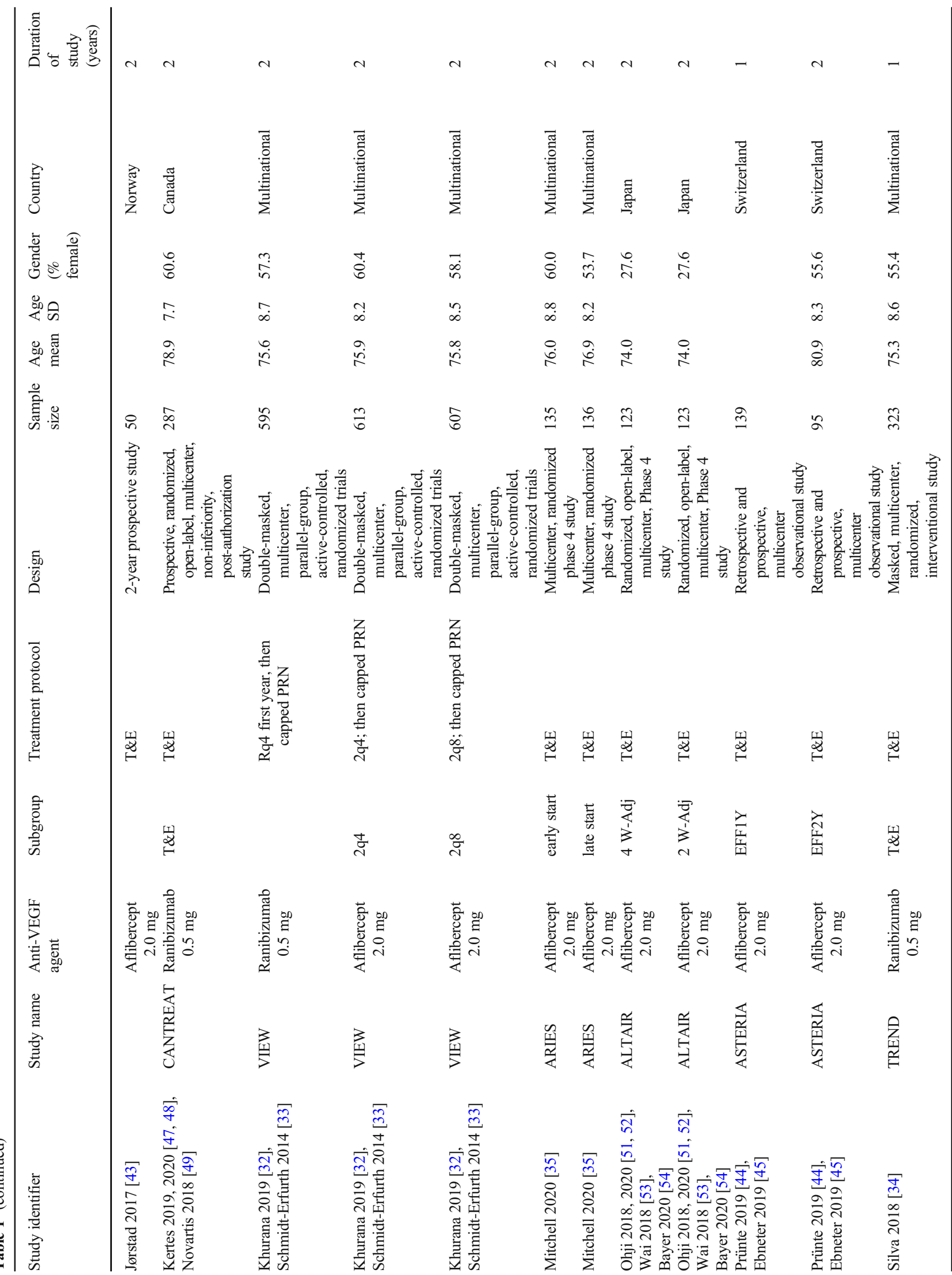


$53.3 \%)$ and after 24 months $(\operatorname{Ran}=34.2 \%, \mathrm{Afl}=47.7 \%, \mathrm{Bro}=$ 41.7\%; Table 2).

Based on a single data set and in the absence of real-life data confirming the trial findings, Bro seems to be superior to the two other drugs respecting absence of fluid as well as interval extension within the first year of treatment $(p=<$ 0.001 each), whereas it remained superior only concerning the absence of fluid after 24 months $(p=<0.001$; Table 2). The portion of eyes without intraretinal fluid declined in year 2 for Ran (from 56.3 to $50.0 \%$ ) and Afl (from 64.5 to $52.7 \%$ ), whereas it increased for Bro (from 71.5 to $75.7 \%$ ). The opposite was observed for the portion of eyes with extended treatment to $\geq 12$ weeks, which was increasing from 12 to 24 months (Ran from 28.6 to $34.2 \%$, Afl from 34.2 to $47.7 \%$ ), but decreasing for Bro (from 53.3 to $41.7 \%$ ).

The overall pooled mean baseline visual acuity was 59.3 ( $\mathrm{SD}=14.0 ; \mathrm{CI}=57.7$ to 60.9$)$ ETDRS letters, while it increased to $67.6(\mathrm{SD}=15.3 ; \mathrm{CI}=66.5$ to 68.8$)$ letters at 12 months and to $65.8(\mathrm{SD}=18.4 ; \mathrm{CI}=63.8$ to 67.7$)$ letters at 24 months of follow-up. The pooled visual gain was 7.4 $(\mathrm{SD}=12.6 ; \mathrm{CI}=6.4$ to 8.4$)$ letters at 12 months and $6.2(\mathrm{SD}=$ $14.7 ; \mathrm{CI}=5.6$ to 6.9 ) letters at 24 months.

The pooled group of Ran and Afl reported a mean of 8.4 $(\mathrm{SD}=1.9 ; \mathrm{CI}=8.1$ to 8.8$)$ injections during the first and 5.9 $(\mathrm{SD}=2.2 ; \mathrm{CI}=5.1$ to 6.7 ) injections during the second year whereas the number of injections was not reported separately for year 1 and 2 for Bro (Table 3).

\section{Discussion}

A realistic aim of treatment under anti-VEGF therapy is to maintain the functional gain and anatomic stability that was achieved by the end of the loading phase [61, 62]. Whereas only $25 \%$ of patients have maximal visual gain by the end of the lading phase, $14 \%$ of patients have gained substantially after that [63]. The fact that the portion of eyes for extension of the treatment to $\geq 12$ weeks increased during the second year from 37.7 to $42.6 \%$ could indicate that disease stability increases over time. This possibility, however, is contradicted by the fact that the number of eyes without retinal fluid went back from 62.9 to $56.0 \%$. Different factors could account for this finding, e.g., a more relaxed treatment extension strategy in year 2. This may, from a functional aspect, be well supportable in the short- and midterm, as demonstrated by the ALTAIR study [51, 52]. Another explanation might be patient adherence to treatment which was generally good but came down from 91.0 to $82.8 \%$. However, the relatively good adherence probably can explain only a minor part of the changes over time. Under-treatment might thus be assumed. Indeed, the number of injections for Ran and Afl in the first year (9.0 and 7.9) compared to 7.4 and 5.2 during the second year indicates a robust reduction, but likely does not represent a 
Fig. 1 PRISMA search flow

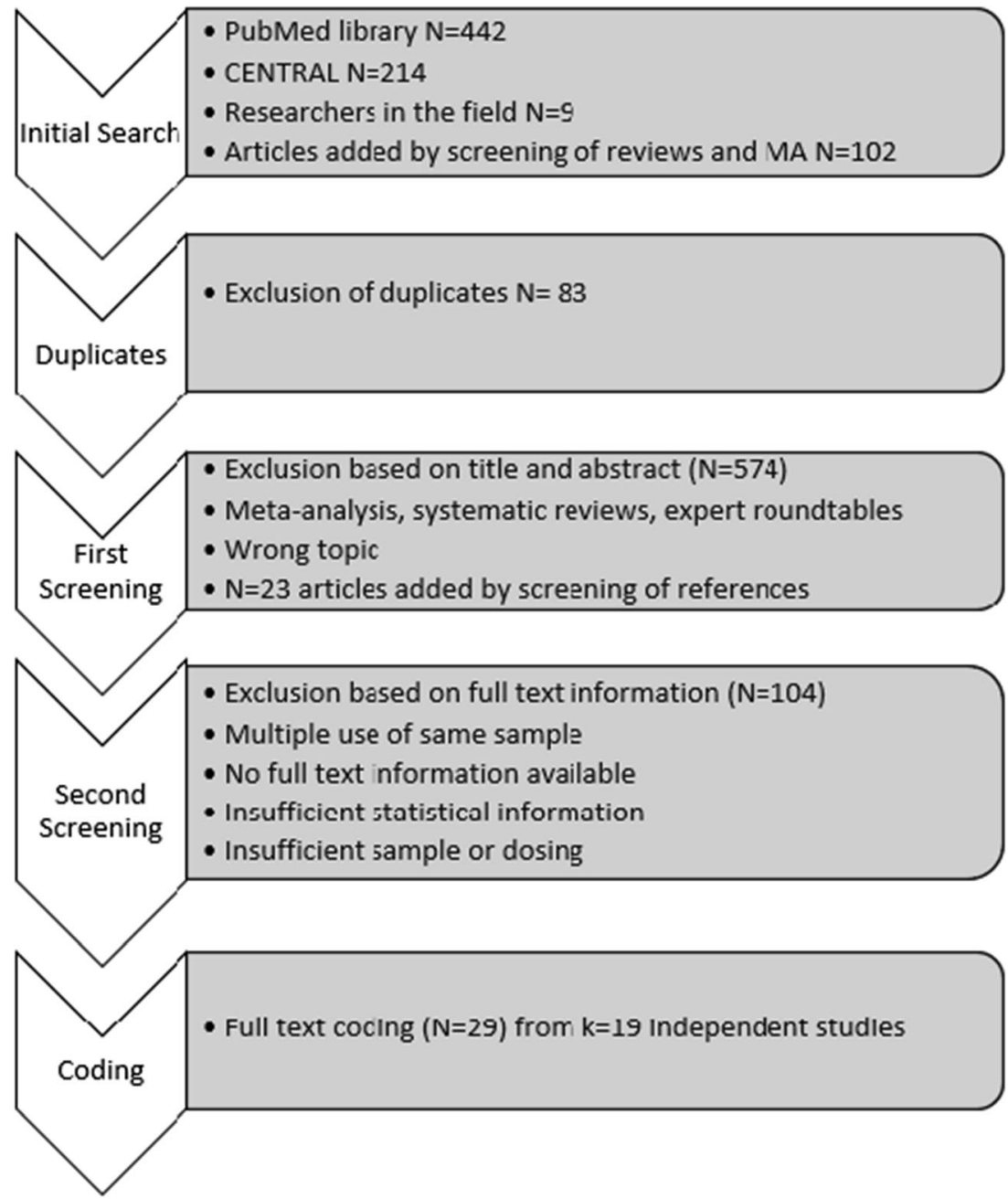

Table 2 Subgroup analysis for the absence of fluid, interval extension and retention rate

\begin{tabular}{|c|c|c|c|c|c|c|c|c|}
\hline & \multicolumn{4}{|c|}{12 months } & \multicolumn{4}{|c|}{24 months } \\
\hline & $n$ & $k_{\mathrm{S}}$ & $\%$ & $p$ & $n$ & $k_{\mathrm{S}}$ & $\%$ & $p$ \\
\hline \multicolumn{9}{|l|}{ Absence of fluid } \\
\hline Ranibizumab $0.5 \mathrm{mg}$ & 1062 & 7 & 56.3 & \multirow[t]{3}{*}{$<0.001$} & 1081 & 5 & 50.0 & \multirow[t]{3}{*}{$<0.00$} \\
\hline Aflibercept $2.0 \mathrm{mg}$ & 442 & 5 & 64.5 & & 1938 & 9 & 52.7 & \\
\hline Brolucizumab $6.0 \mathrm{mg}$ & 730 & 2 & 71.5 & & 646 & 2 & 75.7 & \\
\hline \multicolumn{9}{|c|}{ Interval extension (12 weeks) } \\
\hline Ranibizumab $0.5 \mathrm{mg}$ & 943 & 6 & 28.6 & \multirow[t]{3}{*}{$<0.001$} & 1339 & 7 & 34.2 & \multirow[t]{3}{*}{$<0.00$} \\
\hline Aflibercept $2.0 \mathrm{mg}$ & 770 & 7 & 34.2 & & 2360 & 13 & 47.7 & \\
\hline Brolucizumab $6.0 \mathrm{mg}$ & 730 & 2 & 53.3 & & 646 & 2 & 41.7 & \\
\hline \multicolumn{9}{|l|}{ Retention rate } \\
\hline Ranibizumab $0.5 \mathrm{mg}$ & 943 & 6 & 90.5 & \multirow[t]{3}{*}{0.69} & 1339 & 7 & 81.6 & \multirow[t]{3}{*}{$<0.001$} \\
\hline Aflibercept $2.0 \mathrm{mg}$ & 60 & 2 & 91.0 & & 2266 & 12 & 81.7 & \\
\hline Brolucizumab $6.0 \mathrm{mg}$ & 730 & 2 & 91.6 & & 646 & 2 & 88.6 & \\
\hline
\end{tabular}

$k_{\mathrm{S}}$, number of samples included in the analysis

The $p$ value represents the difference between all three groups 


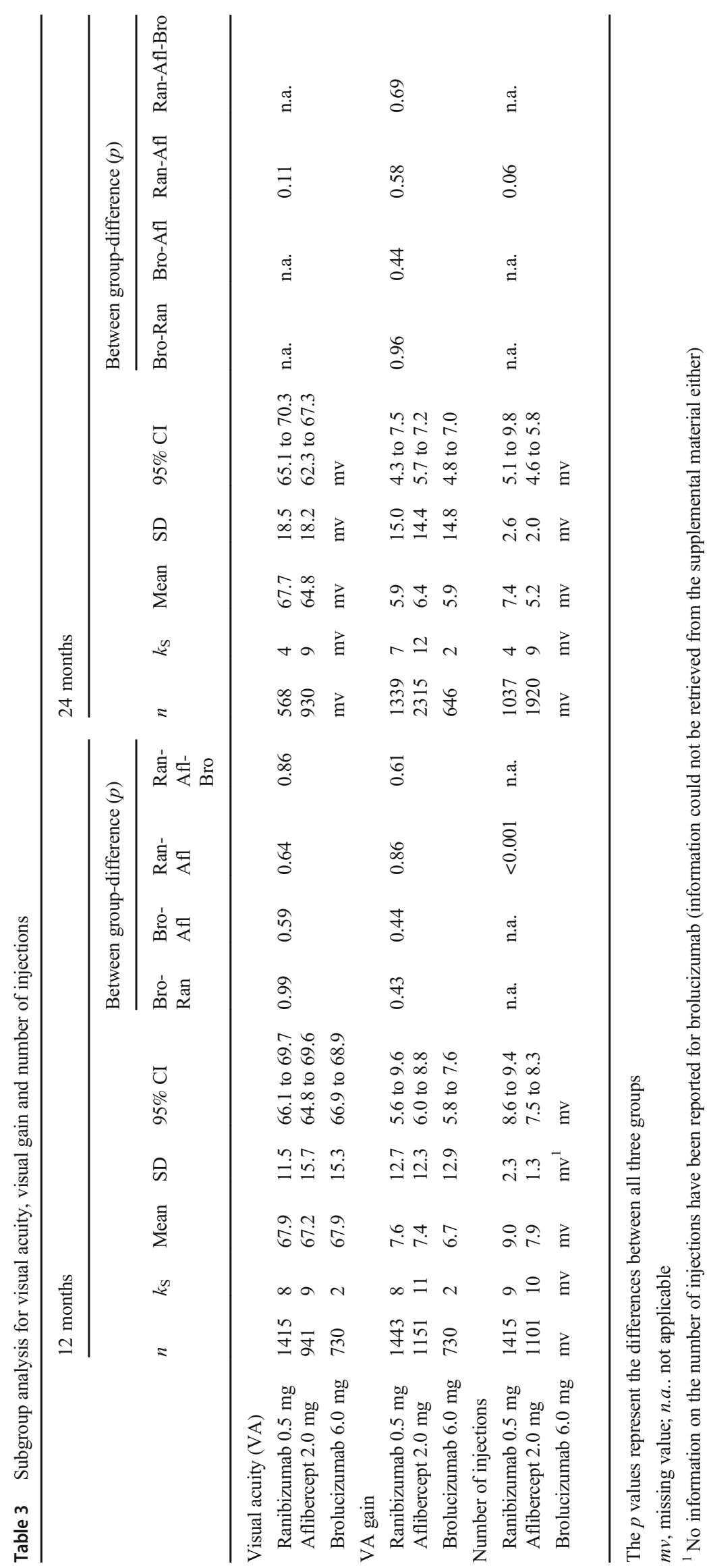


relevant under-treatment and reflects clinical experience [46, 64]. This is also supported by a stable visual function between years one and two (Table 3). It seems that this reflects the challenges in balancing between under-treatment and a reduced treatment burden.

The calculation of the average treatment demand based on the number of injections per year or the mean treatment interval alone seems a rough estimate without taking into account the portion of eyes that changed from a dry situation at the end of year one to a non-dry one at the end of year 2. Disease stability may thus be a more robust marker to predict progression of the disease, but has not routinely been reported in recent series.

A general weakness of analyzing the treatment demand in studies where it is not the primary outcome may derive from the study design which does not reflect the last (possibly best) treatment interval but uses the pre-determined fixed annual time point. A robust calculation of treatment demand would have to include the last treatment extension interval without intra- and/or subretinal fluid before a given time point. It possibly should not be calculated after just 1 year under therapy. Nevertheless, evidence grows that the long-term (3-5 years) visual stability under a T\&E strategy exceeds that of a PRN treatment with its inherent risk of under-treatment [65]. Though until recently only limited level 1 or 2 evidence existed in favor of a T\&E strategy [66], this protocol rapidly found acceptance in many specialized retina centers [67].

Evidence regarding treatment extension beyond $12-$ 14 weeks is scarce $[58,68]$. The risk of severe vision loss, however, was reported to increase disproportionally with any further extension [69] which reflects the pathophysiological experience of the slow recovery of $\mathrm{CNV}$ perfusion after the disappearance of anti-VEGF effects [70-73]. It may thus require good arguments to exceed a treatment interval of 12 14 weeks for Ran and Afl. In contrast, the newer drugs in the pipeline such as faricimab, DARPins, and others as well as the recently approved Bro rise hope to exceed these experiencebased maximal treatment intervals to 16 or more weeks in stable disease [74-77]. Conbercept, whose potential to extend the treatment interval to 12 or more weeks is currently assessed in a phase 3 trial (PANDA, ClinicalTrials.gov registration numbers NCT03577899 and NCT03630952) and seems to evoke a similar potency as Afl according to preliminary data (50). Considering that T\&E protocols had been established systematically only a few years ago, it is not surprising that a manageable number of studies with different protocols provide limited information for treatment extension intervals, and the majority use the 12-month time point. The strength of this meta-analysis, on the other hand, is that it refers to almost 3000 eyes. Our data do not support the assumption that the portion of eyes reaching 12 weekly injection intervals will grow by up to $50 \%$ until 2 years of therapy, remaining widely stable after that regardless of the chosen anti-VEGF therapy [32]. If macular stability is achieved, this may be maintained in a subgroup of patients for up to 8 years $[25,78]$. A baseline visual acuity of $\geq 70$ ETRDS letters and an early satisfying functional response to treatment are more reliable predictors of long-term outcomes than lesion activity at the end of the loading phase [79] which may be outweighed by the presence of intra- and subretinal fluid as well as subretinal fibrosis at the end of the loading phase [80].

The first prospective clinical trial comparing a fixed monthly to a T\&E regimen with Ran for nAMD, the TREX-AMD study, revealed that the T\&E-treated eyes performed comparably to monthly treated ones; treatment interval could be extended to $11-12$ weeks in $26 \%$ and $\geq 12$ weeks in $18 \%$ of patients [56]. The 12-month outcomes were confirmed by a Canadian T\&E study in which the treatment intervals in the T\&E arm were extended to 12 weeks in $29.9 \%$ of Ran-treated eyes [50], and the TREND study [36]. Both were included in our meta-analysis, further supporting these findings, that more than $80 \%$ of eyes treated with Afl in 8 to 9-week intervals may become inactive within the first year if the treatment extension interval is not maximized $[55,81]$ and meets well with preclinical pharmacokinetic data $[82,83]$. Not surprisingly, under a reduced treatment intensity after the first year, the rate of eyes without fluid went back to $71 \%$ after $2-3$ years [55]. Its impact on changes in lesion size has as yet not been shown, but maybe a critical predictor of long-term functional stability.

Finally, it is important to carefully interpret the results. By summing up studies with unavoidable heterogeneity, the strength of conclusions may be limited. Nevertheless, they may provide interesting insight in a field where a direct comparison is not likely available as in the case of anti-VEGF therapies in exudative AMD. This also includes an imbalance in the sample sizes. Bro for example was only represented by two samples. Hence, namely the conclusions pertaining to Bro have to be drawn with the requested care.

In conclusion, disease stability as indicated by the absence of intra- and/or subretinal fluid is achieved in nearly twothirds of eyes after 1 year, but declines under a T\&E protocol to $56.0 \%$ by the end of the second year, indicating a possibly relevant long-term safety signal. This may reflect the challenges in balancing between under-treatment and a reduced treatment burden in the clinical situation.

Authors' contributions JGG was responsible for planning and setting up the project. CG was responsible for data collection, methods, and analysis. Both authors equally worked on writing the paper.

Funding information Open Access funding provided by Bern University of Applied Sciences.

Data availability The data can be obtained upon request from the corresponding author. 


\section{Compliance with ethical standards}

Conflict of interest JGG acts as an advisor for several pharmaceutical companies (AbbVie, Alcon, Allergan, Bayer, Kanghong, Novartis) and contributes to several international industry-sponsored clinical studies. The underlying manuscript is independent of these activities. The author received no direct or indirect support for this study, nor has he conflicting interests with the data that are presented herein. CG has no conflicting interests as well.

Ethical approval This type of study does not require informed consent. As a meta-analysis, this manuscript does not include own samples of human participants or animals.

Editorial assistance, in the form of language editing and correction, was provided by Proof-Reading-Service.com.

\section{Code availability Not applicable.}

Open Access This article is licensed under a Creative Commons Attribution 4.0 International License, which permits use, sharing, adaptation, distribution and reproduction in any medium or format, as long as you give appropriate credit to the original author(s) and the source, provide a link to the Creative Commons licence, and indicate if changes were made. The images or other third party material in this article are included in the article's Creative Commons licence, unless indicated otherwise in a credit line to the material. If material is not included in the article's Creative Commons licence and your intended use is not permitted by statutory regulation or exceeds the permitted use, you will need to obtain permission directly from the copyright holder. To view a copy of this licence, visit http://creativecommons.org/licenses/by/4.0/.

\section{References}

1. Dadgostar H, Waheed N (2008) The evolving role of vascular endothelial growth factor inhibitors in the treatment of neovascular age-related macular degeneration. Eye 22:761-767

2. Rosenfeld PJ, Brown DM, Heier JS, Boyer DS, Kaiser PK, Chung CY, Kim RY, MARINA Study Group (2006) Ranibizumab for neovascular age-related macular degeneration. N Engl J Med 355: 1419-1431

3. Brown DM, Kaiser PK, Michels M, Soubrane G, Heier JS, Kim RY, Sy JP, Schneider S, ANCHOR Study Group (2006) Ranibizumab versus verteporfin for neovascular age-related macular degeneration. N Engl J Med 355:1432-1444

4. Rosenfeld PJ, Moshfeghi AA, Puliafito CA (2005) Optical coherence tomography findings after an intravitreal injection of bevacizumab (avastin) for neovascular age-related macular degeneration. Ophthalmic Surg Lasers Imaging 36:331-335

5. Solomon SD, Lindsley K, Vedula SS, Krzystolik MG, Hawkins BS (2019) Anti-vascular endothelial growth factor for neovascular age-related macular degeneration. Cochrane Database Syst Rev: CD005139. PMCID: PMC4270425

6. Michels S, Schmidt-Erfurth U, Rosenfeld PJ (2006) Promising new treatments for neovascular age-related macular degeneration. Expert Opin Investig Drugs 15:779-793

7. Grisanti S, Ziemssen F (2007) Bevacizumab: off-label use in ophthalmology. Indian J Ophthalmol 55:417-420

8. Hanhart J, Comaneshter DS, Freier Dror Y, Vinker S (2017) Mortality in patients treated with intravitreal bevacizumab for age-related macular degeneration. BMC Ophthalmol 17:189

9. Finger RP, Hoffmann AE, Fenwick EK, Wolf A, Kampik A, Kernt M, Neubauer AS, Hirneiss C (2012) Patients' preferences in treatment for neovascular age-related macular degeneration in clinical routine. Br J Ophthalmol 96:997-1002

10. Frennesson C, Nilsson UL, Peebo BB, Nilsson SE (2010) Significant improvements in near vision, reading speed, central visual field and related quality of life after ranibizumab treatment of wet age-related macular degeneration. Acta Ophthalmol 88:420-425

11. Boulanger-Scemama E, Querques G, About F, Puche N, Srour M, Mane V, Massamba N, Canoui-Poitrine F, Souied EH (2015) Ranibizumab for exudative age-related macular degeneration: a five-year study of adherence to follow-up in a real-life setting. J Fr Ophtalmol 38:620-627

12. Gohil R, Crosby-Nwaobi R, Forbes A, Burton BJ, Hykin P, Sivaprasad S (2016) Treatment satisfaction of patients undergoing ranibizumab therapy for neovascular age-related macular degeneration in a real-life setting. Patient Prefer Adherence 10:949-955

13. Singer MA, Awh CC, Sadda S, Freeman WR, Antoszyk AN, Wong P, Tuomi L (2012) HORIZON: an open-label extension trial of ranibizumab for choroidal neovascularization secondary to age-related macular degeneration. Ophthalmology 119:11751183

14. Rofagha S, Bhisitkul RB, Boyer DS, Sadda SR, Zhang K, SEVEN-UP Study Group (2013) Seven-year outcomes in ranibizumab-treated patients in ANCHOR, MARINA, and HORIZON: a multicenter cohort study (SEVEN-UP). Ophthalmology 120:2292-2299

15. Kumar N, Mrejen S, Fung AT, Marsiglia M, Loh BK, Spaide RF (2013) Retinal pigment epithelial cell loss assessed by fundus autofluorescence imaging in neovascular age-related macular degeneration. Ophthalmology 120:334-341

16. Garweg JG (2016) Atrophy of the macula in the context of its wet, age-related degeneration: an inescapable consequence of antiVEGF therapy? Ophthalmologe 113:1036-1045

17. Regillo CD, Busbee BG, Ho AC, Ding B, Haskova Z (2015) Baseline predictors of 12 -month treatment response to ranibizumab in patients with wet age-related macular degeneration. Am J Ophthalmol 160: 1014-1023.e2

18. Wykoff CC, Ou WC, Croft DE, Payne JF, Brown DM, Clark WL, Abdelfattah NS, Sadda SR, TREX-AMD Study Group (2018) Neovascular age-related macular degeneration management in the third year: final results from the TREX-AMD randomised trial. Br J Ophthalmol 102(4):460-464

19. Wykoff CC, Clark WL, Nielsen JS, Brill JV, Greene LS, Heggen CL (2018) Optimizing anti-VEGF treatment outcomes for patients with neovascular age-related macular degeneration. J Manag Care Spec Pharm 24(2-a Suppl):S3-S15

20. Campochiaro PA, Aiello LP, Rosenfeld PJ (2016) Anti-vascular endothelial growth factor agents in the treatment of retinal disease: from bench to bedside. Ophthalmology 123:78-88

21. Villegas VM, Aranguren LA, Kovach JL, Schwartz SG, Flynn HW Jr (2017) Current advances in the treatment of neovascular age-related macular degeneration. Expert Opin Drug Deliv 14: 273-282

22. Garweg JG, Niderprim SA, Russ HM, Pfister IB (2017) Comparison of strategies of treatment with ranibizumab in newly-diagnosed cases of neovascular age-related macular degeneration. J Ocul Pharmacol Ther 33:773-778

23. Richard G, Monés J, Wolf S, Korobelnik JF, Guymer R, Goldstein M, Norenberg C, Sandbrink R, Zeitz O (2015) Scheduled versus pro re nata dosing in the VIEW trials. Ophthalmology 122:2497-2503

24. Sadda SR, Tuomi LL, Ding B, Fung AE, Hopkins JJ (2018) Macular atrophy in the HARBOR study for neovascular agerelated macular degeneration. Ophthalmology 125:878-886

25. Garweg JG, Zirpel JJ, Gerhardt C, Pfister IB (2018) The fate of eyes with wet AMD beyond four years of anti-VEGF therapy. Graefes Arch Clin Exp Ophthalmol 256:823-831 
26. Heier JS, Brown DM, Chong V, Korobelnik JF, Kaiser PK, Nguyen QD, Kirchhof B, Ho A, Ogura Y, Yancopoulos GD, Stahl N, Vitti R, Berliner AJ, Soo Y, Anderesi M, Groetzbach G, Sommerauer B, Sandbrink R, Simader C, Schmidt-Erfurth U, VIEW 1 and VIEW 2 Study Groups (2012) Intravitreal aflibercept (VEGF trap-eye) in wet age-related macular degeneration. Ophthalmology 119:2537-2548

27. Schmidt-Erfurth U, Kaiser PK, Korobelnik JF, Brown DM, Chong V, Nguyen QD, Ho AC, Ogura Y, Simader C, Jaffe GJ, Slakter JS, Yancopoulos GD, Stahl N, Vitti R, Berliner AJ, Soo Y, Anderesi M, Sowade O, Zeitz O, Norenberg C, Sandbrink R, Heier JS (2014) Intravitreal aflibercept injection for neovascular age-related macular degeneration. Ophthalmology 121:193-201

28. Dugel PU, Koh A, Ogura Y, Jaffe GJ, Schmidt-Erfurth U, Brown DM, Gomes AV, Warburton J, Weichselberger A, Holz FG, HAWK and HARRIER Study Investigators (2020) HAWK and HARRIER: phase 3, multicenter, randomized, double-masked trials of brolucizumab for neovascular age-related macular degeneration. Ophthalmology 127:72-84

29. Dugel PU, Singh RP, Koh A, et al. (2020) HAWK and HARRIER: 96-week outcomes from the phase 3 trials of brolucizumab for neovascular age-related macular degeneration https://www.sciencedirect.com/science/article/pii/ S0161642020305704. Accessed 14 May 2020

30. Borenstein M, Hedges LV, Higgins JPT, Rothstein HR (2014) Comprehensive meta-analysis (CMA) software. Version 3.0

31. Barthelmes D, Nguyen V, Daien V, Campain A, Walton R, Guymer R, Morlet N, Hunyor AP, Essex RW, Arnold JJ, Gillies MC, Fight Retinal Blindness Stud Group (2018) Two-year outcomes of "treat and extend" intravitreal therapy using aflibercept preferentially for neovascular age-related macular degeneration. Retina 38:20-28

32. Khurana RN, Rahimy E, Joseph WA, Saroj N, Gibson A, Vitti R, Berliner AJ, Chu K, Cheng Y, Boyer DS (2019) Extended (every 12 weeks or longer) dosing interval with intravitreal Aflibercept and Ranibizumab in neovascular age-related macular degeneration: post hoc analysis of VIEW trials. Am J Ophthalmol 200: 161-168

33. Schmidt-Erfurth U, Kaiser PK, Korobelnik JF, Brown DM, Chong V, Nguyen QD et al (2014) Intravitreal Aflibercept injection for neovascular age-related macular degeneration: ninety-sixweek results of the VIEW studies. Ophthalmology 121:193-201

34. Silva R, Berta A, Larsen M, Macfadden W, Feller C, Monés J, TREND Study Group (2018) Treat-and-extend versus monthly regimen in neovascular age-related macular degeneration: results with Ranibizumab from the TREND study. Ophthalmology 125: 57-65

35. Mitchell P, Holz FG, Hykin PG, Midena E, Okada AA, Souied EH et al (2020) Comparison of treat-and-extend (T\&E) dosing regimens and visual outcomes in the ARIES and ALTAIR studies of intravitreal aflibercept (IVT-AFL) in neovascular age-related macular degeneration (nAMD). Invest Ophthalmol Vis Sci 61:4219-4219

36. Gillies MC, Hunyor AP, Arnold JJ, Guymer RH, Wolf S, Pecheur FL, Munk MR, McAllister IL (2019) Macular atrophy in neovascular age-related macular degeneration: a randomized clinical trial comparing ranibizumab and aflibercept (RIVAL study). Ophthalmology 127:198-210

37. Gillies MC, Hunyor AP, Arnold JJ, Guymer RH, Wolf S, Pecheur FL, Munk MR, McAllister IL (2019) Effect of ranibizumab and aflibercept on best-corrected visual acuity in treat-and-extend for neovascular age-related macular degeneration: a randomized clinical trial. JAMA Ophthalmology 137:372-379

38. Novartis Pharma AG (2018) Comparison of ranibizumab and aflibercept in patients with nAMD treated following a "treat and extend" protocol: the RIVAL study. ClinTrials.gov Identifier NCT02130024 (last updated June 5, 2019)

39. Guymer RH, Markey CM, McAllister IL, Gillies MC, Hunyor AP, Arnold JJ, on behalf of the FLUID Investigators (2019) Tolerating subretinal fluid in neovascular age-related macular degeneration treated with ranibizumab using a treat-and-extend regimen: FLUID study 24-month results. Ophthalmology 126:723-734

40. Toalster N, Russell M, Paul NG (2013) A 12-month prospective trial of inject and extend regimen for ranibizumab treatment of age-related macular degeneration. Retina 33:1351-1358

41. Berg K, Pedersen TR, Sandvik L, Bragadóttir R (2015) Comparison of ranibizumab and bevacizumab for neovascular age-related macular degeneration according to LUCAS treatand-extend protocol. Ophthalmology 122:146-152

42. Berg K, Hadzalic E, Gjertsen I, Forsaa V, Berger LH, Kinge B et al (2016) Ranibizumab or bevacizumab for neovascular agerelated macular degeneration according to the lucentis compared to avastin study treat-and-extend protocol: two-year results. Ophthalmology 123:51-59

43. Jørstad ØK, Faber RT, Moe MC (2017) Two-year functional and anatomical results after converting treatment resistant eyes with exudative age-related macular degeneration to aflibercept in accordance with a treat and extend protocol. Acta Ophthalmol 95:460-463

44. Prünte C, Michels S, Ebneter A, Imesch P, Eilenberger F, Oesch S, Hatz K (2019) 2-year outcomes of Intravitreal aflibercept in patients with treatment-naïve wet AMD in a Swiss routine practice treat-and-extend regimen: final analysis of the ASTERIA study. Presented at the EURETINA in Paris (France) on Sept 52019

45. Ebneter A, Michels S, Imesch P, Eilenberger F, Oesch S, Prünte C, Hatz K (2019) Intravitreal aflibercept in a routine treat-and-extend (T\&E) regimen for treatment-naïve wet AMD patients: 2-year outcomes of the observational ASTERIA study. Poster presented at the Association for Research in vision and Ophtalmology Annual Meeting, Vancouver, BC, Canada: April 28-May 22019

46. Traine PG, Pfister IB, Zandi S, Spindler J, Garweg JG (2019) Long-term outcome of intravitreal aflibercept treatment for neovascular age-related macular degeneration using a "treat-andextend" regimen. Ophthalmology Retina 3:393-399

47. Kertes PJ, Galic IJ, Greve M, Williams RG, Rampakakis E, Scarino A, Sheidow T (2019) Canadian treat-and-extend analysis trial with ranibizumab in patients with neovascular age-related macular disease: one-year results of the randomized Canadian treat-and-extend analysis trial with ranibizumab study. Ophthalmology 126:841-848

48. Kertes PJ, Galic IJ, Greve M, Williams G, Baker J, Lahaie M, Sheidow T (2020) Efficacy of a treat-and-extend regimen with ranibizumab in patients with neovascular age-related macular disease: a randomized clinical trial. JAMA Ophthalmology 138:244-250

49. Novartis Pharma AG (2018) Canadian treat-and-extend trial with ranibizumab in patients with neovascular AMD: CANTREAT study 2-year results. AAO 2018 Congress Report. ClinicalTrials. gov Identifier NCT02103738 (last updated June 5, 2020)

50. Cui J, Sun D, Lu H, Dai R, Xing L, Dong H, Wang L, Wei D, Jiang B, Jiao Y Jablonski MM, Charles S, Gu W, Chen H (2018) Comparison of effectiveness and safety between conbercept and ranibizumab for treatment of neovascular age-related macular degeneration. A retrospective case-controlled non-inferiority multiple center study. Eye 32: 391

51. Ohji M, Takahashi K, Okada AA, Kobayashi M, Matsuda Y, Terano Y; ALTAIR Investigators (2018) Two different treat-and-extend dosing regimens of intravitreal aflibercept in Japanese patients with wet age-related macular degeneration: 96-week results of the ALTAIR study http://www.euretina.org/congress/vienna-2018/vienna-2018abstracts $/$ ?title=Free\%20Paper\%20Session\%208:\%20AMD\% 20II\&sessiom $=730 \&$ title $=$ Free $\% 20$ Paper $\% 20$ Session $\% 208: \%$ 20AMD $\% 20$ II \&room $=$ Room $\% 20$ D $5 \&$ sesstime $=$ Friday $\% 2021 \%$ 20September\%202018. Accessed 14 May 2020

52. Ohji M, Takahashi K, Okada AA, Kobayashi M, Matsuda Y, Terano Y (2020) Efficacy and safety of intravitreal aflibercept treat-and- 
extend regimens in exudative age-related macular degeneration: 52and 96-week findings from ALTAIR. Adv Ther 37:1173-1187

53. Wai KM, Singh RP (2018) Treat and extend dosing regimen with anti-vascular endothelial growth factor agents for neovascular agerelated macular degeneration. Am J Ophthal Clin Trials: 1

54. Bayer Schweiz AG (2020) Treat-and-Extend bei feuchter AMD Hoher Prozentsatz von Patienten mit 12- und 16-WochenIntervallen unter Eylea®. Supplement ophta 2/2020

55. Eleftheriadou M, Gemenetzi M, Lukic M, Sivaprasad S, Hykin PG, Hamilton RD, Rajendram R, Tufail A, Patel PJ (2018) Threeyear outcomes of aflibercept treatment for neovascular age-related macular degeneration: evidence from a clinical setting. Ophthalmol Therapy 7:361-368

56. Wykoff CC, Croft DE, Brown DM, Wang R, Payne JF, Clark L, Abdelfattah NS, Sadda SR, TREX-AMD Study Group (2015) Prospective trial of treat-and-extend versus monthly dosing for neovascular age-related macular degeneration: TREX-AMD 1year results. Ophthalmology 122:2514-2522

57. Wykoff CC, Ou WC, Brown DM, Croft DE, Wang R, Payne JF et al (2017) Randomized trial of treat-and-extend versus monthly dosing for neovascular age-related macular degeneration: 2-year results of the TREX-AMD study. Ophthalmology Retina 1:314-321

58. DeCroos FC, Reed D, Adam MK, Salz D, Gupta OP, Ho AC, Regillo CD (2017) Treat-and-extend therapy using aflibercept for neovascular age-related macular degeneration: a prospective clinical trial. Am J Ophthalmol 180:142-150

59. Taipale C, Lindholm JM, Laine I, Tuuminen R (2020) Comparison of two different treat-and-extend protocols with aflibercept in wet age-related macular degeneration. Acta Ophthalmol 98:267-273

60. Cohen J (1960) A coefficient of agreement for nominal scales. Educ Psychol Meas 20:37-46

61. Amoaku WM, Chakravarthy U, Gale R, Gavin M, Ghanchi F, Gibson J, Harding S, Johnston RL, Kelly SP, Lotery A, Mahmood S, Menon G, Sivaprasad S, Talks J, Tufail A, Yang Y (2015) Defining response to anti-VEGF therapies in neovascular AMD. Eye 29:721-731

62. Ashraf M, Souka A, Adelman RA (2018) Age-related macular degeneration: using morphological predictors to modify current treatment protocols. Acta Ophthalmol 96:120-133

63. Stoller GL, Kokame GT, Dreyer RF, Shapiro H, Tuomi LL (2016) Patterns of early and delayed visual response to ranibizumab treatment for neovascular age-related macular degeneration. JAMA Ophthalmol 134:545-553

64. Staurenghi G, Garweg JG, Gerendas BS, Macfadden W, Gekkiev B, Margaron P, Dunger-Baldauf C, Kolar P (2020) Functional versus functional and anatomical criteria-guided ranibizumab treatment in patients with neovascular age-related macular degeneration - results from the randomized, phase IIIb OCTAVE study. BMC Ophthalmol 20:18

65. Kim LN, Mehta H, Barthelmes D, Nguyen V, Gillies MC (2016) Meta-analysis of real-world outcomes of intravitreal ranibizumab for the treatment of neovascular age-related macular degeneration. Retina 36:1418-1431

66. Okada M, Kandasamy R, Chong EW, McGuiness M, Guymer RH (2018) The treat-and-extend injection regimen versus alternate dosing strategies in age-related macular degeneration: a systematic review and meta-analysis. Am J Ophthalmol 192:184-197

67. Gemenetzi M, Patel PJ (2017) A systematic review of the treat and extend treatment regimen with anti-VEGF agents for neovascular age-related macular degeneration. Ophthalmol Therapy 6:79-92

68. Mehta H, Tufail A, Daien V, Lee AY, Nguyen V, Ozturk M, Barthelmes D, Gillies MC (2018) Real-world outcomes in patients with neovascular age-related macular degeneration treated with intravitreal vascular endothelial growth factor inhibitors. Prog Retin Eye Res 65:127-146
69. Essex RW, Nguyen V, Walton R, Arnold JJ, IL MA, Guymer RH, Morlet N, Young S, Barthelmes D, Gillies MC, Fight Retinal Blindness Study Group (2016) Treatment patterns and visual outcomes during the maintenance phase of treat-and-extend therapy for age-related macular degeneration. Ophthalmology 123:23932400

70. Faatz H, Farecki ML, Rothaus K, Gutfleisch M, Pauleikhoff D, Lommatzsch A (2019) Changes in the OCT angiographic appearance of type 1 and type $2 \mathrm{CNV}$ in exudative AMD during antiVEGF treatment. BMJ Open Ophthalmol 4(1):e000369

71. McClintic SM, Gao S, Wang J, Hagag A, Lauer AK, Flaxel CJ, Bhavsar K, Hwang TS, Huang D, Jia Y, Bailey ST (2018) Quantitative evaluation of choroidal neovascularization under pro re nata anti-vascular endothelial growth factor therapy with OCT angiography. Ophthalmol Retina 2(9):931-941

72. Uchida A, Hu M, Babiuch A, Srivastava SK, Singh RP, Kaiser PK, Talcott K, Rachitskaya A, Ehlers JP (2019) Optical coherence tomography angiography characteristics of choroidal neovascularization requiring varied dosing frequencies in treat-and-extend management: an analysis of the AVATAR study. PLoS One 14(6):e0218889

73. Miere A, Oubraham H, Amoroso F, Butori P, Astroz P, Semoun O, Bruyere E, Pedinielli A, Addou-Regnard M, Jung C, Cohen SY, Souied EH (2018) Optical coherence tomography angiography to distinguish changes of choroidal neovascularization after anti-VEGF therapy: monthly loading dose versus pro re nata regimen. J Ophthalmol 4:3751702

74. Sahni J, Patel SS, Dugel PU, Khanani AM, Jhaveri CD, Wykoff CC, Hershberger VS, Pauly-Evers M, Sadikhov S, Szczesny P, Schwab D, Nogoceke E, Osborne A, Weikert R, Fauser S (2019) Simultaneous inhibition of angiopoietin-2 and vascular endothelial growth factorwith faricimab in diabetic macular edema: BOULEVARD phase 2 randomized trial. Ophthalmology 126:1155-1170

75. Souied EH, Devin F, Mauget-Faÿsse M, Kolář P, WolfSchnurrbusch U, Framme C, Gaucher D, Querques G, Stumpp MT, Wolf S, MP0112 Study Group (2014) Treatment of exudative age-related macular degeneration with a designed ankyrin repeat protein that binds vascular endothelial growth factor: a phase I/II study. Am J Ophthalmol 158:724-732.e2

76. Al-Khersan H, Hussain RM, Ciulla TA, Dugel PU (2019) Innovative therapies for neovascular age-related macular degeneration. Expert Opin Pharmacother 20:1879-1891

77. Dugel PU, Jaffe GJ, Sallstig P, Warburton J, Weichselberger A, Wieland M, Singerman L (2017) Brolucizumab versus aflibercept in participants with neovascular age-related macular degeneration: a randomized trial. Ophthalmology 124:1296-1304

78. Berg K, Roald AB, Navaratnam J, Bragadóttir R (2017) An 8-year follow-up of anti-vascular endothelial growth factor treatment with a treat-and-extend modality for neovascular age-related macular degeneration. Acta Ophthalmol 95:796-802

79. Nguyen V, Daien V, Guymer R, Young S, Hunyor A, Fraser-Bell S, Hunt A, Gillies MC, Barthelmes D, Fight Retinal Blindness! Study Group (2019) Projection of long-term visual acuity outcomes based on initial treatment response in neovascular agerelated macular degeneration. Ophthalmology 126:64-74

80. Sagiv O, Zloto O, Moroz I, Moisseiev J (2017) Different clinical courses on long-term follow-up of age-related macular degeneration patients treated with Intravitreal anti-vascular endothelial growth factor injections. Ophthalmologica 238:217-225

81. Barthelmes D, Nguyen V, Walton R, Gillies MC, Daien V, Fight Retinal Blindness Study Group (2018) A pharmacoepidemiologic study of ranibizumab and aflibercept use 2013-2016. The Fight Retinal Blindness! Project. Graefes Arch Clin Exp Ophthalmol 256: 1839-1846

82. Stewart MW, Rosenfeld PJ (2008) Predicted biological activity of intravitreal VEGF trap. Br J Ophthalmol 92:667-668 